\title{
Journal of Speech Pathology \& Therapy
}

\section{Do Events on One Day Influence the Perception of Stuttering on Subsequent Days?}

Susanne Cook ${ }^{*}$, Chris Donlan, I. Chris McManus and Peter Howell

Division of Psychology and Language Science, University College London, Gower Street, London, United Kingdom

*Corresponding author: Susanne Cook, Division of Psychology and Language Science, University College London, Gower Street, London, United Kingdom Tel: +442076797566; Email: susanne.cook@me.com

Received date: April 11, 2016, Accepted date: May 26, 2016, Published date: June 02, 2016

Copyright: @ 2016 Cook S, et al. This is an open-access article distributed under the terms of the Creative Commons Attribution License, which permits unrestricted use, distribution, and reproduction in any medium, provided the original author and source are credited.

\begin{abstract}
Objective: The reaction of children and adolescents who stutter to their own speech and their perception about how others reacted to them were examined over time. Day-to-day changes in perception of own-speech and emotional impact of others on their stuttering were assessed using the new Daily Questionnaire.
\end{abstract}

Design: Nineteen participants (mean age13.10 years, SD=2.8 years) who attended an intensive stuttering treatment completed the Daily Questionnaire on 19 successive days.

Results: The Daily Questionnaire assessed day-to-day experiences of the participants and the influence these experiences had on the participant's life. Significant cross-lagged panel correlations between the impact of other people's behavior on the previous day with perception of general speaking abilities on the current day were found and between the emotions reported on the previous day and the perception of their own speaking abilities on the current day.

Conclusions: The experiences of children and adolescents who stutter fluctuated over time because of the perception of their own and other people's behavior. These perceived experiences affected how the participants perceived their speech on subsequent days.

Keywords: Children and Adolescents who Stutter; Day-to-day Experiences; Perception; Impact of Stuttering; Treatment; Affect; Fluency Disorder

\section{Introduction}

It is necessary to document the outcome of treatments in speech pathology and health issues in general. Outcome research in stuttering has focussed mainly either on overt symptom changes [1-4] or on qualitative changes in affective behavior [5-8]. While it is important to assess both these domains [9], other outcomes need monitoring too. Yaruss suggested that one factor that may influence treatment outcome was the diverse experience of people who stutter during intervention and in their lives in general [10]. An example of such experiences is given in the qualitative study of Hearne, Packman, Onslow and Quine about stuttering during the adolescent years; in that study, two participants reported that their supportive network of friends shielded them against teasing by others [11]. Participants also reported that group therapy was preferred to individual therapy as working with others who deal with similar problems was motivating and more closely related to the real world. Erickson and Block described how adolescents who stutter viewed their own communicative competency as below average, showed apprehension towards communicating with others, and experienced more teasing and bullying than fluent peers [12]. This is in line with the study of Blood and Blood who also found that adolescents who stutter rated themselves as having lower communicative competencies than their fluent peers, and were at a higher risk of experiencing bullying [13]. While it seems obvious that such diverse experiences could influence treatment outcomes, the question that arises is how such influences could be measured?

The topic of measuring the impact of diverse experiences on treatment outcomes has been examined in allied health areas such as stress disorders [14-17]. In stress disorders research, one approach has been to establish how major life events mediate stress levels. One study showed that while such life events had an impact on stress levels, they were only responsible for a small portion of the change in observable stress-related symptoms [17]. Another approach has focused on the minor life events and seeing whether fluctuations in these relate to an individual's stress as experienced in daily life [16]. Studies have shown that the changes in these minor daily events are better predictors of stress level, psychological distress and negative affect, than major life events $[14,15,17,18]$ Brantley et al. developed the Daily Stress Inventory (DSI), a standardized, valid and reliable 58-item self-report instrument for adults to assess the impact of minor daily stressful events on a person's life. After identifying events one has experienced in the past 24 hours, the respondent rates the stressfulness of the event on a 7-point Likert scale ( $1=$ "occurred but was not stressful" to $7=$ "caused me to panic"). Blood, Wertz, Blood, Bennett and Simpson documented the perceived daily stress in adults who stutter and compared it with adults who did not stutter [19]. Apart from subjective and objective measurements of stuttering severity, Blood et al. [19] measured the participants' life stress with the Social Readjustment Rating Scale [20] and the participants' daily stressors with the DSI [18] for 22 consecutive days. No difference in life stressors between the two subgroups was found. Results of the Daily Stress Inventory showed that the subgroup of people who stutter identified a higher number of daily 
'hassles' as stressors, this included a higher number of daily stressors with regard to interpersonal problems. Half of these interpersonal problems were related to speaking performance. The study also found that daily stressors were associated with an increase in dysfluent speech.

The present study examined whether changes in reported daily experiences were related to reports about stuttering More specifically, the study analysed whether the reports about how a participant felt about his or her speech from the previous day affected their reports on the current day. These findings fill the gap in knowledge about the relation of stuttering and minor life events with children and adolescents. The fluctuations in daily experiences were measured during a three-week intensive therapy program. The hypothesis was a child or adolescent's rating of comparatively minor daily events, such as a reaction of another person towards a dysfluency on the previous day will be correlated with changes in self-ratings on the following day.

Testing this hypothesis required that daily events and experiences of children and adolescents who stutter were measured over a period of time. The Daily Questionnaire (see Appendix) was developed which assesses how participants felt on the current day compared with the previous day. The four domains assessed were perceptions about: 1) speech in general, 2) stuttering; 3) communication environments; and 4) interlocutor stance in speaking situations.

The data from the Daily Questionnaire were used to assess the underlying relationships between reports of daily experiences, emotional lability and experienced quality of life. In particular, the relationships between events on one day and how the participant felt about his or her stuttering on the following day were assessed.

\section{Methods}

All methods were approved by the UCL Research Ethics committee with the project ID number 1403/001.

\section{Participants}

Nineteen German children and adolescents who stutter aged between 9.0 years and 17.7 years $(\mathrm{M}=13.10$ years, $\mathrm{SD}=2.8$ years) participated in the study. There were 13 boys and six girls. Each participant was diagnosed with stuttering by his or her referring doctor and by the first author, a native German speaker and speech language pathologist a certified stuttering specialist (ivs) (a national board certification for fluency disorders in Germany). Stuttering severity was assessed as being between mild and very severe using a translation of version three of the Stuttering Severity Instrument (SSI-3) [21]. Information for each participant with regard to gender, age, and stuttering severity before treatment is given in Table 1 . The children and adolescents participated in a residential three-week intensive therapy treatment. The concept behind the therapy was based on a combination of a stuttering-modification approach and fluency shaping techniques. During this intensive therapy course $[22,23,24]$, components of the stuttering modification therapy according Van Riper were combined with speech-techniques which focused on speech rhythm and getting participants to produce sounds with soft onsets $[25,26]$, and awareness-exercises [22]. One-on-one sessions were provided in addition to the aforementioned group therapy. During the first week of the intensive phase, identification and analysis of fluent and stuttered speech took place. The goal of the subsequent desensitization phase (week 2) was to desensitise against negative emotions towards talking and stuttering. During the modification phase (week 3) different methods for altering current stuttering behaviours were introduced, such as pull-out [24] or speech techniques focusing on speech rhythm and soft onsets [25]. As a residential program, the participants and the therapeutic team spent time together during therapy and for the remainder of the day. Besides the therapy intervention, other daily activities, for example morning sports, evening entertainment (improv theater, game night, movie night etc.) were offered. During the three-week program, several field trips took place to transfer the newly learned skills into the "real world". This intensive therapy provided maximum opportunity for generalization of skills from therapy situations to leisure time. Additionally, the children and adolescents could see that they are not alone with their stuttering, and they could motivate and help each other to deal with it.

\begin{tabular}{cccc}
\hline Number & Gender & $\begin{array}{c}\text { Age } \\
\text { (years.months) }\end{array}$ & Stuttering severity \\
\hline 1 & Female & 14.2 & 17 \\
2 & Female & 17.7 & 41 \\
3 & Male & 17.3 & 22 \\
4 & Male & 10.4 & 30 \\
5 & Female & 13.0 & 7 \\
6 & Female & 16.11 & 27 \\
7 & Male & 13.5 & 28 \\
8 & Female & 14.2 & 7 \\
9 & Male & 11.10 & 33 \\
10 & Male & 12.2 & 30 \\
11 & Male & 17.2 & 26 \\
12 & Male & 16.3 & 25 \\
13 & Female & 13.3 & 33 \\
14 & Male & 15.10 & 16 \\
15 & Male & 15.4 & 17 \\
16 & Male & 9.1 & 17 \\
17 & Male & 14.11 & 24 \\
18 & Male & 11.2 & 32 \\
19 & Male & 9.0 & 29 \\
\hline
\end{tabular}

Table 1: Gender, age and stuttering severity before treatment measured with SSI-3 of all participants.

\section{Instrument to assess day-to-day changes: The daily questionnaire}

Development: The Daily Questionnaire was designed to collect information about the participants' perceptions towards their stuttering. The Daily Questionnaire contained 25 questions each of which was assessed according to a six-point Likert scale format (Figure 1). Each question required participants to assess how they currently felt about some aspect relative to the day before. The questions were arranged in four sections: (A) General information about speech (four items); (B) Feelings about stuttering (six items); (C) Different speaking situations (nine items); and (D) Impact of stuttering on their life (six items). A pilot study was completed to determine readability among the targeted age demographic and how long it takes to complete the questionnaire. The Daily Questionnaire was given to ten children and adolescents who stuttered between the ages of 9.11 years and 17.11 years. An exit survey about participants' experiences was given to pilot 
study participants, which inquired about their perceived readability and duration of taking the survey. Results of that survey revealed that the pilot participants ranked the Daily Questionnaire as easy to understand, and the survey takes approximately five minutes to complete. Data from these participants were not included in the subsequent analysis.

Scoring procedure: Each of the 25 questions received a score of between 1 and 6 on the Likert scale (points indicated in Figure 1). Questions A1 to A4, B3, B5, B6, C1, C3 to C6, C8, and D1 to D6 were scored as follows: Strongly agree $=1$, Agree $=2$, Somewhat agree $=3$, Somewhat disagree $=4$, Disagree $=5$, Strongly disagree $=6$. Questions B1, B2, B4, C2, C7, and C9 were rated in reverse (e.g. Strongly agree $=6$, and Strongly disagree $=1$ ). The valence was changed because the questions in the first group were indications of positive affect, and those in the second group were indications of negative affect. The total raw score for a participant was obtained by adding up responses to all items, resulting in scores between 25 and 150; high scores indicate more negative perceptions toward stuttering; conversely, lower scores are indicative of less negative affect.

\section{Procedure}

Copies of the questionnaire were distributed to the group of 19 children and adolescents who stuttered every evening after the therapy sessions and the participants completed them on their own in a quiet room. Investigators noted that the three youngest children took approximately 10 extra minutes to complete the Daily Questionnaire; thus, speech language pathology students read the questions aloud and allowed the children to point to responses for the next 18 out of 19 survey days. Per investigator judgment, and per statement of the three participants, they did not have a problem interpreting the questions; throughout the study, the three youngest participants provided relevant, consistent responses to questionnaire items and verbal comments regarding questionnaire responses indicative of understanding. For example, when answering question C3, a child said, "I am picking 'agree,' because I raised my hand to answer a question during group today. I haven't felt confident enough to do that before. All 19 participants completed the Daily Questionnaire on 19 successive days. This resulted in a total of 361 datasets.

\section{Results}

\section{Distribution of scores}

Analyses of the 361 questionnaires showed that the data were slightly positively skewed (Figure 2) with a skewness coefficient of +0.354 . The positive skew is typical with such measures, as most people answer that they feel fine about the issues they are interrogated about.

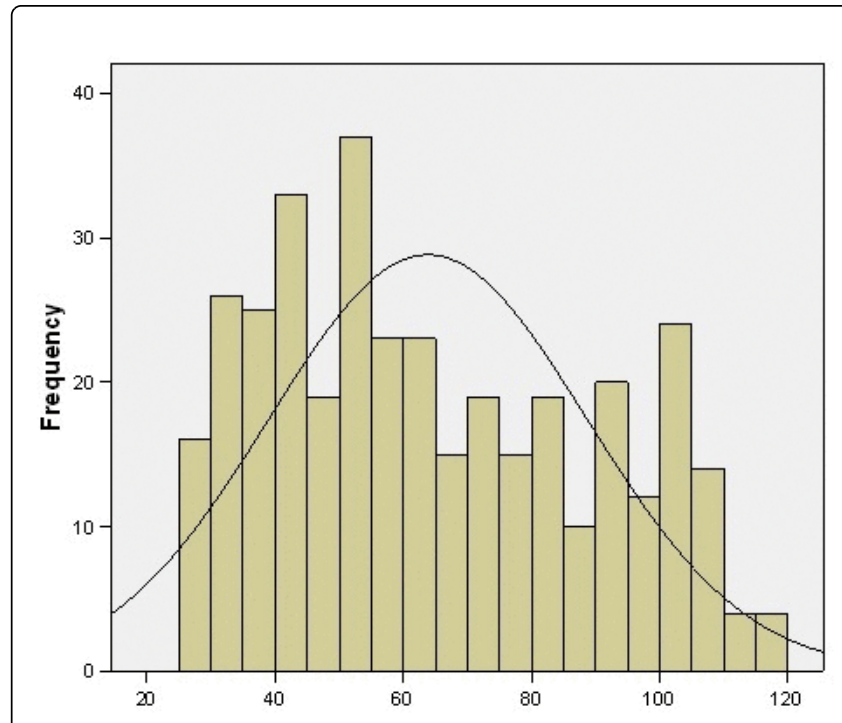

Figure 1: Histogram showing distribution of scores of the Daily Questionnaire with normal distribution curve fitted. X-Axis: Total overall score for the Daily Questionnaire. Y-Axis: Frequency of scores.

\section{Reliability}

Internal reliability was assessed using Cronbach's $\alpha$, and the value was 0.920 . A value of $\alpha$ between 0.7 and 0.8 is an acceptable value for internal reliability [27]. Kline noted that when dealing with psychological constructs, even a value below 0.7 is acceptable if the construct being measured includes diverse components [28]. The itemtotal statistics given in Table 2 showed whether removing an item improved the overall reliability of the scale. Alpha increased when questions B1, B2, B4, C2, C7, and C9 were removed. However, overall reliability did not increase significantly when these questions were taken out. Consequently, these questions were retained. Cronbach's $a$ was 0.921 for subscale A (general perceptions about stuttering), 0.580 for subscale B (feelings towards stuttering), 0.761for subscale C (different speaking situations) and 0.899 for subscale D (impact of stuttering). Cronbach's Alpha for subscale B was poor, which might be due to the fact that some of these questions were not applicable every day, for example, question B3 and B6 both provide a double-statement, "When I think about my stuttering today, I feel less anxious/ embarrassed than yesterday/not anxious/embarrassed at all." Overall, the internal reliability calculations confirmed that the Daily Questionnaire had good reliability. A test-retest-reliability measure was not carried out because the questionnaire was designed to assess daily changes.

\section{Validity}

Content validity: A comparison was made between the Daily Questionnaire and The World Health Organization's (WHO) "International Classification of Functioning, Disability and Health" (ICF, WHO, 2001) in order to assess content validity [29]. The ICF looks at health-related experiences of the individual at multiple levels that represent a person's abilities and experiences [8]. The ICF focuses on function and disability along the four dimensions 'Body Functions 
and Body Structure, 'Activity and Participation', 'Environmental Factors', and 'Personal Factors'.

\begin{tabular}{lc}
\hline $\boldsymbol{\alpha}$ if & item \\
\hline deleted \\
A2 & 0.915 \\
A3 & 0.913 \\
A4 & 0.914 \\
B1 & 0.915 \\
B2 & 0.921 \\
B3 & 0.922 \\
B4 & 0.917 \\
B5 & 0.915 \\
B6 & 0.917 \\
C1 & 0.913 \\
C2 & 0.922 \\
C3 & 0.913 \\
C4 & 0.915 \\
C5 & 0.912 \\
C6 & 0.913 \\
C7 & 0.927 \\
C8 & 0.914 \\
C9 & 0.928 \\
D1 & 0.918 \\
D2 & 0.914 \\
D3 & 0.912 \\
D4 & 0.914 \\
D5 & 0.912 \\
D6 & 0.912 \\
\end{tabular}

Table 2: Item-total statistics for the Daily Questionnaire

Together these allow description of fluent speech and dysfluencies, as well as other positive and negative aspects of the experience of fluent and stuttered speech by the person who stutters. A detailed description of a model that displays features of stuttering as a disorder is given in Yaruss and Quesal [8]. All four dimensions in the ICF are addressed in the items of the Daily Questionnaire. The component 'Body Functions' is addressed in questions A1 and A3. The component 'Personal Factors' is addressed in questions $\mathrm{B} 1$ to $\mathrm{B} 6$, and D4 to D6. The component 'Activity/Participation' is addressed in questions A4, C1, and C3 to C9, D3 and D6. The category 'Environmental Factors' is addressed in questions A4, C2, and D1 to D4.

Factor analysis: Each participant's responses were standardized to that child's own mean and standard deviation by converting them to zscores (conversion of a distribution of observations into $\mathrm{z}$-scores gives a distribution with a mean of 0 and a standard deviation of 1 according to Field) [27]. Transformation to z-scores eliminates response bias (e.g., participants who always either checked that they felt good or that they felt bad). After z-transformation each child's scores were located around the common mean.

Factor analysis was carried out using the FACTOR program of SPSS 13.0 using principal component extraction and Varimax rotation. Factor analysis is a multivariate technique that identifies relationships between a set of observed variables (in this study the questions of the Daily Questionnaire) and whether there is a potentially lower number of unobserved variables called factors [27]. Factor analysis results can be used to reduce the set of variables in the dataset to just those that work. Varimax rotation attempts to maximize the dispersion of factor loadings within factors by trying to load smaller numbers of variable highly onto each factor. This results in more interpretable clusters of factors (Field, 2009).

A scree plot is a graph that displays each factor in a factor analysis ( $x$-axis) against its associated eigenvalue ( $y$-axis) in a descending order. It shows the relative importance of each factor and can help to visually assess which components or factors explain most of the variability in the data [27]. The scree plot for the Daily Questionnaire showed the impact of the components extracted by the factor analysis on the $\mathrm{z}$ score data (Figure 2). The first four factors were deemed to represent the four categories in the Daily Questionnaire. These four factors explained $44.52 \%$ of the variance. The rotated component matrix of the z-score data is given in Table 3. High positive values indicated correlation between subsets of questions. For better readability of the table, only the highest scores for each question are reported. Component 1 loaded on the complete subset $\mathrm{D}$ and also on the questions B3, B5 and B6. These questions can be summarized as "Impact of others" and "Confidence in dealing with stuttering". Component 2 loaded all of the questions of subset $\mathrm{A}$ as well as on the questions $\mathrm{C} 3$ and $\mathrm{C} 4$. These questions can be summarized as "My speaking abilities in general". Component 3 loaded on questions B1, B2, B4, C5, C6 and C8. This set of questions can be summarised as "Emotions". Component 4 loaded on questions B6, C2, C3, C4, C7, and C9, and can be described as "Specific speaking situations" (see Table 3).

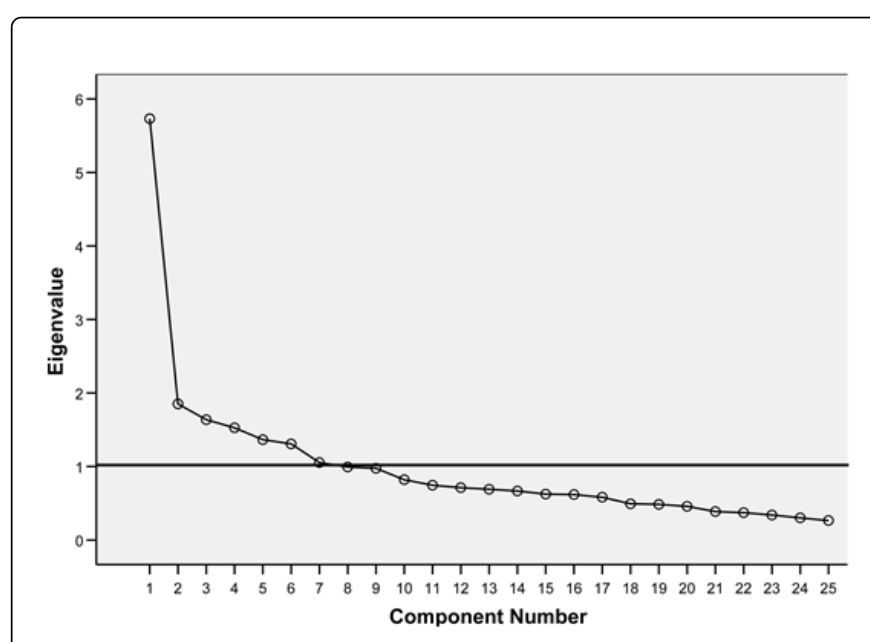

Figure 2: Scree plot of the factor analysis for the Daily Questionnaire using z-scores

The factor analysis suggested that there are four main dimensions that underlie the Daily Questionnaire and the interpretation suggests that these may reflect sub-components of the day-to-day experiences of the children and adolescents who stutter (Impact of other people; 
Page 5 of 9

General speaking abilities; Specific speaking situations and Emotions). The relation of factors, categories and corresponding questions of the Daily Questionnaire can be found in Table 4. It is important to note that the factors weight on several items.

\begin{tabular}{|c|c|c|c|c|}
\hline & \multicolumn{4}{|c|}{ Components } \\
\hline & 1 & 2 & 3 & 4 \\
\hline $\begin{array}{l}\text { score A1 } \\
\text { Speech sounded more natural }\end{array}$ & & .773 & & \\
\hline $\begin{array}{l}Z \text { score } \mathrm{A} 2 \\
\text { Easier to say exactly what intended to say }\end{array}$ & & \begin{tabular}{|l}
.647 \\
\end{tabular} & & \\
\hline $\begin{array}{l}2 \text { score } A 3 \\
\text { Overall speaking ability is better }\end{array}$ & & .816 & & \\
\hline $\begin{array}{l}2 \text { score A4 } \\
\text { Better application of learned techniques }\end{array}$ & & .711 & & \\
\hline $\begin{array}{l}Z \text { score B1 } \\
\text { More helpless }\end{array}$ & & & \begin{tabular}{|l}
.507 \\
\end{tabular} & \\
\hline $\begin{array}{l}\text { Z score B2 } \\
\text { More angry or frustrated }\end{array}$ & & .350 & .404 & \\
\hline $\begin{array}{l}\text { score B3 } \\
\text { Less anxious } \\
\end{array}$ & .458 & & & \\
\hline $\begin{array}{l}\text { score B4 } \\
\text { More isolated }\end{array}$ & & & .679 & \\
\hline $\begin{array}{l}\text { score B5 } \\
\text { More self-confident }\end{array}$ & .612 & & & \\
\hline $\begin{array}{l}\text { score B6 } \\
\text { Less embarrassed }\end{array}$ & .472 & & & .454 \\
\hline $\begin{array}{l}Z \text { score } \mathrm{C} 1 \\
\text { Avoiding less speaking situations }\end{array}$ & & & & .510 \\
\hline $\begin{array}{l}7 \text { score } \mathrm{C} 2 \\
\text { Let other people tall for me }\end{array}$ & & & & $\begin{array}{l}-330 \\
\end{array}$ \\
\hline $\begin{array}{l}Z \text { Z score C3 } \\
\text { Easier to speak to adults }\end{array}$ & & .481 & & \begin{tabular}{|l|l|}
.278 \\
\end{tabular} \\
\hline $\begin{array}{l}\text { score } \mathrm{C} 4 \\
\text { Easier to speak when in a hurry or upset }\end{array}$ & .301 & \begin{tabular}{|c|c|}
.417 \\
\end{tabular} & & .313 \\
\hline $\begin{array}{l}Z \text { score C5 } \\
\text { Easier to speak to someone one-on-one }\end{array}$ & .322 & .278 & .426 & \\
\hline $\begin{array}{l}Z \text { score C6 } \\
\text { Easier to speak to a small group of people }\end{array}$ & .319 & .342 & .510 & \\
\hline $\begin{array}{l}Z \text { score C7 } \\
\text { Harder to speak to a large group of people }\end{array}$ & & & & $-2,613$ \\
\hline $\begin{array}{l}7 \text { score } \mathrm{CB} \\
\text { Easier to speak on the phone }\end{array}$ & .272 & & .561 & \\
\hline $\begin{array}{l}Z \text { score C9 } \\
\text { Harder to speak to peers }\end{array}$ & & & & -.563 \\
\hline $\begin{array}{l}Z \text { score D1 } \\
\text { Reactions of others were more positive }\end{array}$ & .468 & & & \\
\hline $\begin{array}{l}\text { Z score D2 } \\
\text { I got less bullied/not bullied at all }\end{array}$ & .557 & & & \\
\hline $\begin{array}{l}Z \text { score D3 } \\
\text { Easier to make friends }\end{array}$ & .562 & & & \\
\hline $\begin{array}{l}\text { Z score D4 } \\
\text { More knowledge about how to deal with stuttering }\end{array}$ & .597 & .302 & & \\
\hline $\begin{array}{l}\text { I score D5 } \\
\text { I feel more brave }\end{array}$ & .711 & & & \\
\hline $\begin{array}{l}\text { score D6 } \\
\text { It was easier to make own decisions }\end{array}$ & .677 & & & \\
\hline
\end{tabular}

Table 3: Rotated component matrix for the Daily Questionnaire.

The Kaiser-Meyer-Olkin Measure of Sampling Adequacy (KMO) was used next to determine the statistical fit of the factor analysis. The KMO for the Daily Questionnaire was 0.845 , which according to Field is a good result (high scores on KMO indicate that the factor analysis was appropriate) [27]. Although factor analysis is useful for understanding the dimensionality and structure of underlying factors, Varimax rotation in particular has the problem that correlations between the factors are forced to zero, which may not be a fair constraint to apply to the actual data, and can make interpretation of results difficult. In interest of not complicating results interpretation and because the factor analysis had identified four factors corresponding to the $\mathrm{A}, \mathrm{B}, \mathrm{C}$ and $\mathrm{D}$ items, scores were extracted for each participant individually, on the mean of the four $\mathrm{A}$, six $\mathrm{B}$, nine $\mathrm{C}$ and six D scores, The mean of the A, B, C, and D scores were standardized separately so that scores for each participant had a mean of zero and a standard deviation of one. These scores were then used for the remaining analyses. To avoid confusion, these scores are called $\mathrm{zA}, \mathrm{zB}, \mathrm{zC}$ and $\mathrm{zD}$. The scores of the previous day are called $\mathrm{zAp}, \mathrm{zBp}$, $\mathrm{zCp}$ and $\mathrm{zDp}$ (z-scores relating to the previous day) and the scores of the current day are called $\mathrm{zAc}, \mathrm{zBc}, \mathrm{zCc}$ and $\mathrm{zDc}$ ( $\mathrm{z}$-scores relating to the current day).

\begin{tabular}{llll}
\hline $\begin{array}{l}\text { Factor/ } \\
\text { Component }\end{array}$ & Category & $\begin{array}{l}\text { Corresponding } \\
\text { Questions }\end{array}$ & Description \\
\hline 1 & zD & D1-D6, B3, B5, B6 & Impact of other people \\
2 & zA & A1-A4, C3, C4 & General speaking abilities \\
3 & zB & B1, B2, B4, C5, C6, C8 & Emotions \\
4 & zC & C1-C4, C7, C9 & Specific speaking situations \\
\hline
\end{tabular}

Table 4: Overview over factors, categories and corresponding questions of the Daily Questionnaire.

\section{Model of changes in day-to-day experiences of CWS during a three-week treatment}

The correlations between $\mathrm{zAc}, \mathrm{zBc}, \mathrm{zCc}$ and $\mathrm{zDc}$ and $\mathrm{zAp}, \mathrm{zBp}, \mathrm{zCp}$ and $\mathrm{zDp}$ were calculated using multiple regression analysis, which takes the interrelationship between the variables into account [30]. In other words, responses of the current day $(\mathrm{zAc}, \mathrm{zBc}, \mathrm{zCc}$ and $\mathrm{zDc}$ ) were correlated with the responses of the previous day (zAp, zBp, zCp and $\mathrm{zDp}$ ). Predictor variables were the factors on the previous day; outcome variables were the factors on the current day. Since each participant had data from nineteen days, there were eighteen current day-previous day pairs. The multiple regressions served two functions: (1) to assess how well these variables together contributed to predicting how a participant felt on the current day and (2) how well each variable on its own (for example "impact of others" or "emotions") related to how a participant felt on the current day. The analysis used LISREL 8.80 [31] to identify cross-lagged correlations between the four factors between the previous day and the current day. LISREL is a software program that is able to deal with a wide variety of models for the analysis of latent variables. A cross-lagged correlation examined the predictive association between different variables at different time points [32]. In this study the correlation of the four "previous day" factors with the "current day" factors were analysed to assess whether prior everyday occurrences were related to changes of feelings towards stuttering on the current day. The correlation matrix of the correlations between the "previous day" factors (zAp - General speaking abilities, zBp -Emotions, zCp - Specific Speaking situations and zDp - Impact of other people on self) and the "current day" factors (zAc - General speaking abilities, zBc -Emotions, zCc - Specific Speaking situations and $\mathrm{zDc}$ - Impact of other people on self) is given in Table 5. Most of the coefficients along the diagonal of Table 5, which are autocorrelations, were significant. These significant correlations revealed that if a participant rated an event high on the previous day, he or she also tended to rate this event high on the current day. This finding of correlations between ratings on back to back days demonstrated that particular correlations between factors persisted across at least a twoday period (i.e. one day lag) for individuals. The authors also looked at longer lags, of two and three days. None of the autocorrelations were significant for three day lags $(r=-0.032$ for $z A$; $r=-0.032$ for $z B$; $r=-0.046$ for $z C, r=0.002$ for $z D$ ), and only one ( $z B$ - Emotions, 
Citation: Cook S, Donlan C, McManus IC, Howell P (2016) Do Events on One Day Influence the Perception of Stuttering on Subsequent Days? .

$\mathrm{r}=0.104[\mathrm{p}=0.049])$ was significant for a two day lag $(\mathrm{r}=0.070$ for $\mathrm{zA}$, 0.053 for $\mathrm{zC}$ and 0.048 for $\mathrm{zD})$.

\begin{tabular}{llllll}
\hline & & $\begin{array}{l}\text { PD Factor 1 } \\
\text { zDp } \\
\text { Impact of Other } \\
\text { People }\end{array}$ & $\begin{array}{l}\text { PD Factor 2 } \\
\text { zAp } \\
\text { General Speaking } \\
\text { Abilities }\end{array}$ & $\begin{array}{l}\text { PD Factor 3 } \\
\text { zBp } \\
\text { Emotions }\end{array}$ & $\begin{array}{l}\text { PD Factor 4 } \\
\text { zCp } \\
\text { Specific Speaking } \\
\text { Abilities }\end{array}$ \\
\hline CD Factor 1 & Pearson Corr. & $.296^{* *}$ & .087 & .062 & .037 \\
zDc & Sig. (2-tailed) & $<.001$ & .107 & .254 & .498 \\
\hline CD Factor 2 & Pearson Corr. & $.173^{* *}$ & $.289^{* *}$ & $.108^{*}$ & .068 \\
zAc & Sig. (2-tailed) & .001 & $<.001$ & .046 & .212 \\
\hline CD Factor 3 & Pearson Corr. & -.066 & -.047 & $.135^{*}$ & -.091 \\
zBc & Sig. (2-tailed) & .226 & .385 & .013 & .092 \\
\hline CD Factor 4 & Pearson Corr. & .012 & .040 & .043 & -.028 \\
zCc & Sig. (2-tailed) & .823 & .457 & .430 & .605 \\
\hline
\end{tabular}

Table 5: Correlations between the factors of the Current Day $(\mathrm{zDc}, \mathrm{zAc}, \mathrm{zBc}, \mathrm{zCc})$ and Previous Day $(\mathrm{zDp}, \mathrm{zAp}, \mathrm{zBp}, \mathrm{zCp}){ }^{* *}$ indicates a significance level of $\mathrm{p}<.001$. $^{*}$ indicates a significance level of $\mathrm{p}<.05 \mathrm{PD}=$ Previous Day, $\mathrm{CD}=\mathrm{Current}$ Day

Significant correlations were observed for the following autocorrelations between the previous day and the current day.

$\mathrm{zDp}$ to $\mathrm{zDc}$ : the impact of others perceived on the previous day had a highly significant influence on how others were perceived on the current day (Pearson's correlation $\mathrm{r}=0.296, \mathrm{p}<0.001$ ).

zAp to zAc: the person's own speaking abilities perceived on the previous day had a highly significant influence on how their speaking abilities were perceived on the current day (Pearson's correlation $\mathrm{r}=0.289, \mathrm{p}<0.001)$.

$\mathrm{zBp}$ to $\mathrm{zBc}$ : the perception of emotions on the previous day had a significant influence on the perception of emotions on the current day (Pearson's correlation $\mathrm{r}=0.135, \mathrm{p}=0.013$ ).

Factor four (zC - specific speaking situations) was not significant, which might suggest that it has a short half-life where half-life is the amount of time that has to elapse before the knowledge about a particular area is superseded. Experiences with respect to specific situations on the previous day did not seem to have a direct influence on how the participant felt in specific speaking situations on the current day.

The off-diagonal correlations, the cross-lagged correlations (which were crossed from one variable to another and lagged in time) are of particular interest for this study, as they show how different factors relate over time $[33,34]$. These can be used to see if pairs of factors influence experiences in a positive way. A path diagram of the observed correlations between the factor scores on the previous day and the factor scores on the current day is given in Figure 3.

Significant correlations were observed between zDp (Impact of other people on self on the previous day) and zAc (General speaking abilities on the current day). The relation between $\mathrm{zDp}$ and $\mathrm{zAc}$ showed that the impact of others as perceived on the previous day had a highly significant influence on how their own speaking abilities were perceived on the current day (Pearson's correlation $\mathrm{r}=0.173, \mathrm{p}=$ 0.001). The positive correlation indicated that if this impact was experienced in a positive way, the participant seemed to have more confidence in his or her own speaking abilities on the following day. Furthermore, this correlation also proved to be significant over two days $(\mathrm{r}=0.158, \mathrm{p}=0.003)$, but not over three days $(\mathrm{r}=0.041, \mathrm{p}=0.448)$. However given that the autocorrelations for $\mathrm{zD}$ and $\mathrm{zA}$ were not significant for a two-day lag, this result should be treated with caution.

A significant correlation was observed between zBp (emotions on the previous day) and zAc (general speaking abilities on the current day). This relation showed the perception of own emotions on the previous day had a significant influence on how their own speaking abilities were perceived on the current day (Pearson's correlation $\mathrm{r}=0.108, \mathrm{p}=0.046)$. This correlation was not significant over a two day lag $(\mathrm{r}=0.091, \mathrm{p}=0.095)$ or a three day lag $(\mathrm{r}=-0.070, \mathrm{p}=0.198)$. Questions loading on the factor "emotions" dealt, for example, with anxiety and feelings of helplessness or isolation. Again, the positive correlation indicated that a more positive perception of own emotions (feeling more in control of own emotions on the previous day) resulted in an individual feeling better about own speaking abilities on the current day. No significant correlations were found between the factor "Specific speaking situations" (zCp or zCpc) and any other factors. 


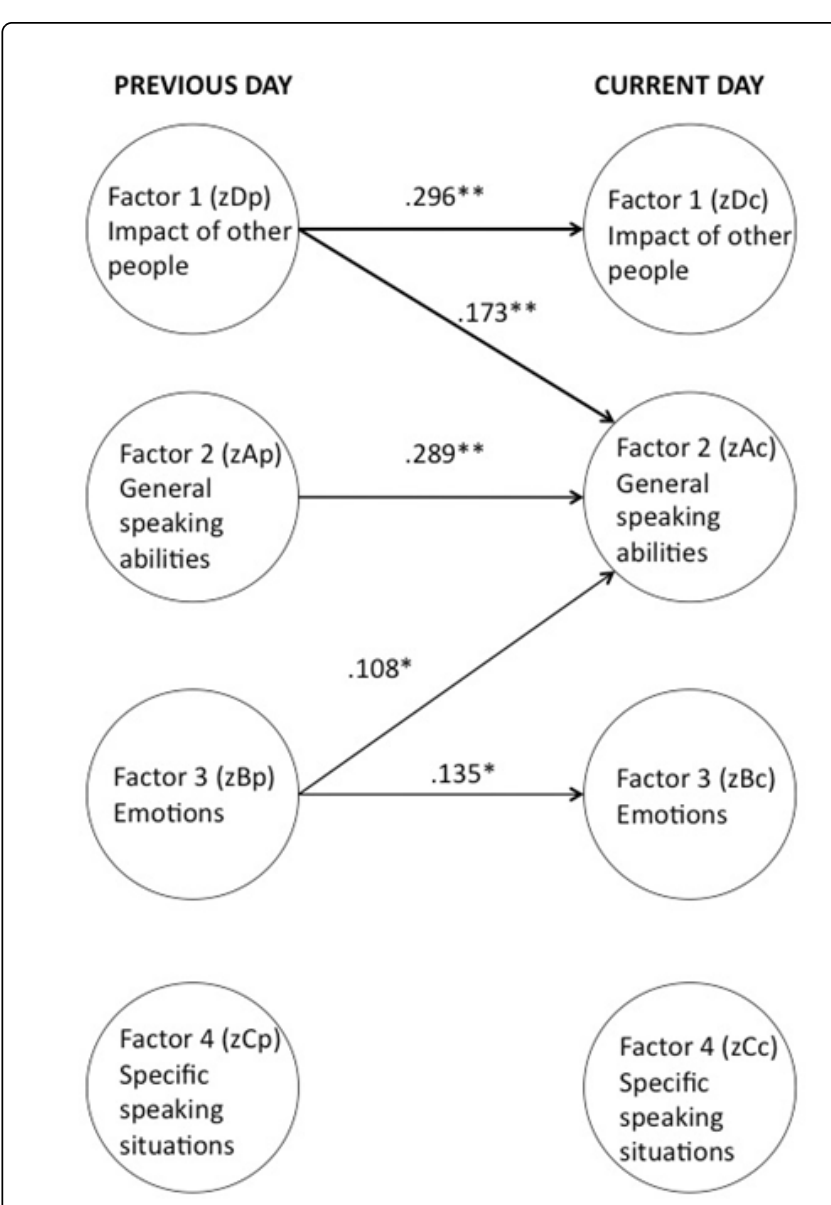

Figure 3: Path diagram of the correlations between factorl (Impact of other people), factor 2 (General speaking abilities), factor 3 (Emotions), and factor 4 (Specific speaking situations). ${ }^{* *}$ Indicates a significance level of $\mathrm{p}<0.001 .{ }^{*}$ indicates a significance level of $\mathrm{p}<0.05$.

\section{Discussion}

The purpose of this study was to examine whether daily changes have an effect on how a child or adolescent who stutters perceives his or her own speech on the current day in relation to the previous day. The results need to be assessed bearing in mind that this study was carried out during an intensive stuttering therapy treatment, which itself might have influenced the perceptions regarding daily hassles. A new questionnaire, the Daily Questionnaire was developed to evaluate day-to-day experiences of children and adolescents who stutter during an intensive therapy intervention. It was hypothesized that events occurring on the previous day mediated how participants experienced their speech on the current day. This hypothesis was supported. The cross-lagged panel correlation between the extracted factors revealed a significant relationship between the impact of other people on the previous day and the experience of general speaking abilities on the current day. Further analysis showed that this correlation was also significant over a two-day lag, but not over three days. This suggests that how others were reacting towards the participant and his or her speech on the previous day not only had an influence on how confident the participant felt in terms of dealing with his or her stuttering on the current day but that this carried on to the following day. Furthermore, a correlation between emotions such as isolation, helplessness and anger towards stuttering on the previous day and experience of own speaking abilities on the current day also occurred. Questions regarding the factor "general speaking abilities" dealt with the naturalness of speech, whether the participant was able to apply his or her techniques and able to say what he or she wanted to say, even in more challenging speaking situations (e.g. being upset or speaking to adults). The findings suggested that on a daily basis during the threeweek intensive treatment, reactions of others influenced how a participant experienced their own speaking abilities on the following day. When applying these results to everyday life, a positive or negative reaction of a teacher or classmate could have a long-lasting effect on the child. Therapists, teachers and parents could take advantage of this relationship when working with children and adolescents who stutter by encouraging positive reactions towards their speech and thereby enhancing the child's confidence in their speaking abilities. A small change such as a positive reaction towards a dysfluency seemed to help the participant to feel more confident about his or her speech and such positive feelings were carried over to the following day.

These results are in agreement with the study of Blood et al. who found that adults who stutter identified more daily hassles than did fluent speakers [19]. 50\% of these stressors dealt with communication issues such as speaking performance or dealing with a superior. Blood et al. suggested that it might be possible to alter the "threshold level of annoyance" during therapy interventions, for example, with desensitization exercises, positive self-talk or problem-solving strategies [19]. Findings of the present study showed that experiences of the previous day are correlated with next-day feelings about speech. It could prove to be useful to adapt desensitization exercises, positive self-talk and problem strategies for interventions with children and adolescents.

\section{Limitations and further research}

This research was carried out with one group of children and adolescents who stutter participating in a three-week intensive treatment. The participants were aged between nine and 17 years, which is a wide age range with respect to social-emotional development differences between children and older adolescents [35]. Children may perceive and react to their stuttering differently than adolescents. The small number of participants did not allow for a separate analysis with two age groups, however, this is planned for future work.

It would be interesting to investigate day-to-day dependencies in the subjective experience of stuttering in an everyday context, for example when children attend school. The setting of an intensive therapy is a relatively protected environment, and although the participants were confronted with their speech problem constantly, they also had the support of the group. This is in agreement with the study of Hearne et al. with adolescents and young adults who also found that group therapy had a positive effect on participants who wanted to be with people sharing the same interests and problems [11]. The situation may be different when the children go to school, as they may be the only person who stutters and the environment (other students, teachers, different classes) is constantly changing. The day-to-day impact of events may be even more pronounced than in a protected therapy setting. Furthermore it would be of interest to see what impact major events, such as changing schools, or a change in a family situation have on a child who stutter, which could be assessed in a longitudinal study. 
Page 8 of 9

In addition, the question could be raised as to whether the reported effects have an impact on speech fluency measures. This could be an indicator of how perceived experiences of stuttering (covert factors) relate to measurable overt behaviour. Such insight would be important as it could help identify a correlation between covert and overt stuttering behavior.

\section{Conclusion}

It has been demonstrated that daily experiences mediate feelings towards stuttering in children and adolescents who stutter in an intensive three-week therapy. The Daily Questionnaire assesses these day-to-day experiences, which makes it possible to assess the microstructure of perceptions of children and adolescents who stutter regarding their stuttering.

\section{Appendix}

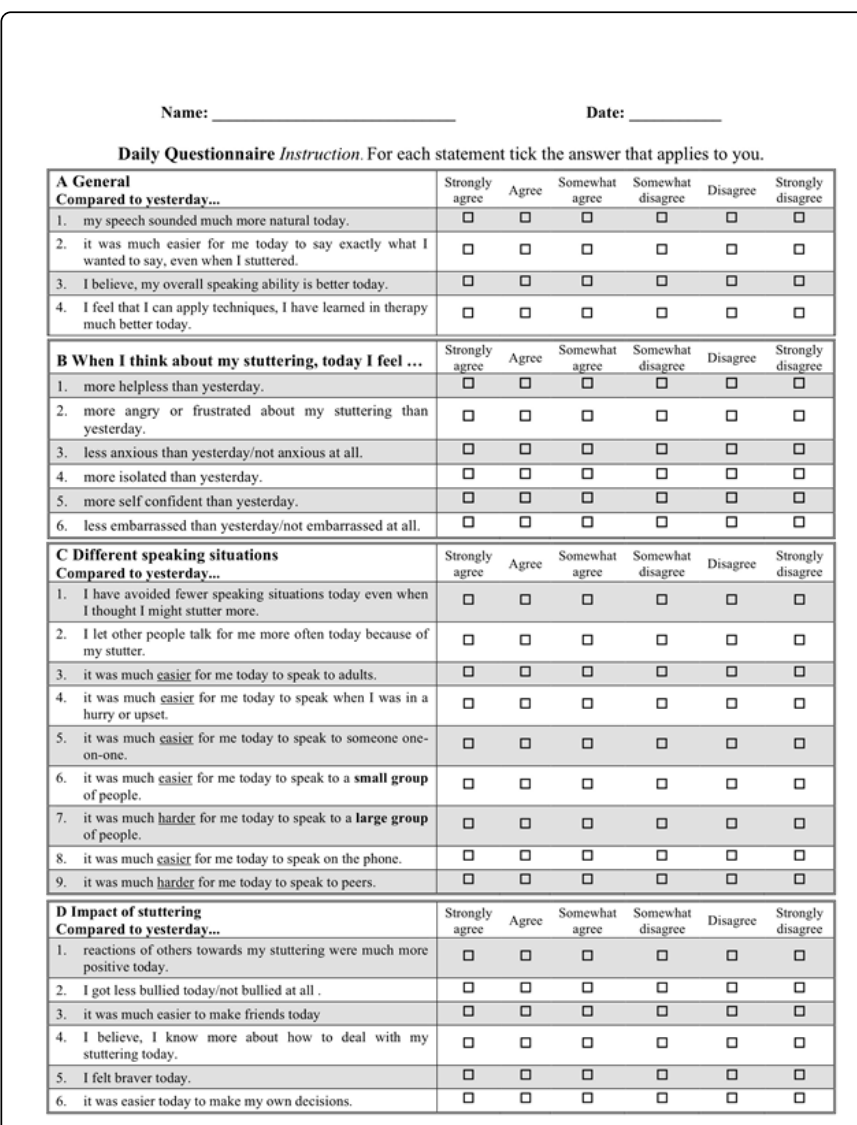

Appendix 1: Daily Questionnaire.

\section{References}

1. Boberg E, Kully D (1994) Long-term results of an intensive treatment program for adults and adolescents who stutter. J Speech Hear Res 37: 1050-1059.

2. Ingham RJ, Kilgo M, Ingham JC, Moglia R, Belknap H, et al. (2001) Evaluation of a stuttering treatment based on reduction of short phonation intervals. J Speech Lang Hear Res 44: 1229-1244.
3. O'Brian S, Onslow M, Cream A, Packman A (2003) The camperdown program: Outcomes of a new prolonged-speech treatment model. Journal of Speech, Language, and Hearing Research : 46: 933-946.

4. Onslow M, Costa L, Andrews C, Harrison E, Packman A (1996) Speech outcomes of a prolonged-speech treatment for stuttering. J Speech Hear Res 39: 734-749.

5. Craig A, Blumgart E, Tran Y (2009) The impact of stuttering on the quality of life in adults who stutter. J Fluency Disord 34: 61-71.

6. Rosenberger S, Metten C, Schulte K (2007) Stotterintensivtherapie Susanne Rosenberger- Erste Ergebnisse einer Evaluationsstudie (Intensive Stuttering Therapy Susanne Rosenberger- First Results of an Evaluation Study). Forum Logopädie 21: 20-25.

7. Yaruss JS (2010) Assessing quality of life in stuttering treatment outcomes research. J Fluency Disord 35: 190-202.

8. Yaruss JS, Quesal RW (2006). Overall assessment of the speaker's experience of stuttering (OASES): Documenting multiple outcomes in stuttering treatment. Journal of Fluency Disorders, 31: 90-115.

9. Blomgren M, Roy N, Callister T, Merrill RM (2005) Intensive stuttering modification therapy: a multidimensional assessment of treatment outcomes. J Speech Lang Hear Res 48: 509-523.

10. Yaruss JS (2004) Documenting individual treatment outcomes in stuttering therapy. Contemporary Issues in Communication Science and Disorders, 31: 49-57.

11. Hearne A, Packman A, Onslow M, Quine S (2008) Stuttering and its treatment in adolescence: the perceptions of people who stutter. J Fluency Disord 33: 81-98.

12. Erickson S, Block S (2013) The social and communication impact of stuttering on adolescents and their families. J Fluency Disord 38: 311-324.

13. Blood GW, Blood IM (2004) Bullying in adolescents who stutter: Communicative competence and self-esteem. Contemporary Issues in Communication Science and Disorders, 31: 69-79.

14. Bolger N, DeLongis A, Kessler RC, Schilling EA (1989) Effects of daily stress on negative mood. J Pers Soc Psychol 57: 808-818.

15. Kanner AD, Coyne JC, Schaefer C, Lazarus RS (1981) Comparison of two modes of stress measurement: daily hassles and uplifts versus major life events. J Behav Med 4: 1-39.

16. Lazarus RS, Folkman S (1984) Stress, appraisal, and coping. New York: Springer Pub Co.

17. Wagner BM, Compas BE, Howell DC (1988) Daily and major life events: a test of an integrative model of psychosocial stress. Am J Community Psychol 16: 189-205.

18. Brantley PJ, Waggoner CD, Jones GN, Rappaport NB (1987) A Daily Stress Inventory: development, reliability, and validity. J Behav Med 10: 61-74.

19. Blood IM, Wertz H, Blood GW, Bennett S, Simpson KC (1997) The effects of life stressors and daily stressors on stuttering. J Speech Lang Hear Res 40: 134-143.

20. Holmes TH, Rahe RH (1967) The Social Readjustment Rating Scale. J Psychosom Res 11: 213-218.

21. Riley G (1994). Stuttering severity instrument for children and adults third edition (3rd ed.). Austin, Texas: Pro-Ed.

22. Rosenberger S (2002) Therapie-Sommercamp für stotternde Kinder und Jugendliche (Therapy Summer Camp for Children and Adolescents Who Stutter). L.O.G.O.S. Interdisziplinär 10: 251-258.

23. Metten C, Zückner H, Rosenberger S (2007) Evaluation einer Stotterintensivtherapie mit Kindern und Jugendlichen. Sprache Stimme Gehör 31: 72-78.

24. Van Riper C (1973) The treatment of stuttering. Englewood Cliffs NJ Prentice-Hall.

25. Herziger F (2007) Spüren - erkennen - verändern (feel - identify change). MitSprache 2: 25-34.

26. Watson D (1992) Correcting for Acquiescent Response Bias in the Absence of a Balanced Scale: An Application to Class Consciousness. Sociological Methods \& Research 21: 52-88.

27. Field A (2009) Discovering statistics using SPSS. Sage publications. 
Citation: Cook S, Donlan C, McManus IC, Howell P (2016) Do Events on One Day Influence the Perception of Stuttering on Subsequent Days? . J Speech Pathol Ther 1: 113. doi:10.4172/jspt. 1000113

Page 9 of 9

28. Kline P (1999) The handbook of psychological testing (2nd edn) London: Routledge.

29. World Health Organization (2001) The international classification of functioning, disability and health: A new tool for understanding disability and health. Geneva

30. Miles J, Gilbert P (2005) A handbook of research methods for clinical and health psychology. New York: Oxford University Press.

31. Jöreskog K, Sörbom (1996) LISREL 8. [8.8] [Computer Software]. Scientific Software International, Inc.
32. Kenny DA, Judd CM (1996) A general procedure for the estimation of interdependence. Psychol Bull 119: 138-148.

33. Kenny DA (1975) Cross-lagged panel correlation: A test for spuriousness. Psychological Bulletin 82: 887.

34. Steiger JH (1980). Tests for comparing elements of a correlation matrix. Psychological Bulletin 87: 245.

35. Sokol, Justin T (2009) Identity Development Throughout the Lifetime: An Examination of Eriksonian Theory. Graduate Journal of Counseling Psychology, 1: Article 14 